\title{
POSITIVE REGULATION OF MACROMOLECULE METABOLIC PROCESS BELONGS TO THE MAIN MECHANISMS CRUCIAL FOR PORCINE OOCYTES MATURATION
}

\author{
Wiesława KRANC ${ }^{1}$, Piotr CELICHOWSKI ${ }^{2}$, Joanna BUDNA ${ }^{2}$, Ronza KHOZMI ${ }^{1}$, \\ Artur BRYJA ${ }^{1}$, Sylwia CIESIÓŁKA ${ }^{2}$, Marta RYBSKA ${ }^{3}$, Sylwia BORYS ${ }^{1}$, \\ Michal JESETA ${ }^{4}$, Dorota BUKOWSKA ${ }^{3}$, Paweł ANTOSIK ${ }^{3}$, \\ Klaus P. BRÜSSOW ${ }^{1}$, Małgorzata BRUSKA ${ }^{1}$, Michał NOWICKI ${ }^{1}$, \\ Maciej ZABEL ${ }^{2}$, Bartosz KEMPISTY ${ }^{1,2}$ \\ ${ }^{1}$ Department of Anatomy, Poznan University of Medical Sciences, Poznan, Poland \\ ${ }^{2}$ Department of Histology and Embryology, \\ Poznan University of Medical Sciences, Poland \\ ${ }^{3}$ Institute of Veterinary Sciences, Poznan University of Life Sciences, Poland \\ ${ }^{4}$ Department of Obstetrics and Gynecology, University Hospital and Masaryk \\ University, Brno, Czech Republic
}

DOI: $10.1515 / \mathrm{acb}-2017-0002$

Summary: The mammalian oocytes maturation is the compound process that involves morphological and molecular changes. These modifications include storage of macromolecules, which are crucial for proteins biosynthesis during periimplantation stages of embryo development. This study was aimed to investigate the genes expression profile encoding macromolecules important for regulation of proper porcine oocytes maturation.

The porcine oocytes were collected from large ovarian follicles and analyzed both before and after in vitro maturation (IVM). Additionally, to check the developmental competence status, brilliant crezyl blue test (BCB) was performed. The obtained cDNA was used for biotin labeling and fragmentation by AffymetrixGeneChip ${ }^{\circledR}$ WT Terminal Labeling and Hybridization (Affymetrix). The preliminary analysis of the scanned chips was performed using AffymetrixGeneAtlasTM Operating Software. The created CEL files were imported into downstream data analysis software.

In results, we found expression of 419 different genes, 379 genes were down-regulated and 40 genes were up-regulated in relation to the oocyte transcriptome before in vitro procedure. We observed up-regulation of all genes involved in "positive regulation of macromolecule metabolic process" before IVM as compared to transcriptional profile analyzed after IVM. 
In conclusion, we suggested that genes encoding proteins involved in macromolecule metabolism are important for achieving of porcine oocytes maturational stage. Moreover, the "activity of macromolecules metabolism" is much more increased in immature oocytes.

Keywords: pig, oocytes, microarray, in vitro maturation (IVM)

\section{INTRODUCTION}

The proper growth and development of mammalian oocytes is substantially regulated by follicular environment and is accompanied by function of surrounding follicular somatic cells. Since the follicular cells such as; theca cells (TCs) and granulosa cells (GCs) secrete hormones that regulates the growth of oocyte inside the single follicle, it may be recognized as self-functioned structure. This unique structure is organized as morphological, biochemical and metabolomic ,unit”, where cell-to cell communication displayed a substantial role in its function. Moreover the cell adhesion and cell contact seem to be significant for follicle existence as the main structure for female gametes production and function. It was well described that in proper growth, development of oocytes during folliculogenesis and oogenesis as well as finally gamete's maturation is engaged with the oocyte-cumulus cells (CCs) communication. Additionally, it was found that the proper oocytes-CCs ,dialog" belongs to the most important prerequisite for gametes maturation. The oocyte-CCs cross-talk is formed by special molecular connections, known also as conexons, which are built by conexins. This unique structure allows the transfer of small molecules in bi-directional pathways between an oocytes and CCs. Our recent experiments indicate that these connections, called also as gap-junction (GJC), belongs to the main structural part not only in CCs but also in separated porcine GCs. These data first demonstrated that GJC are composed of conexins built of a huge protein structure, which may be recognized as one of the most important mechanism involved in follicular-oocyte „dialog”. It is suggested that whole follicle may form a huge structure of cells that are connected all together by compound cross-talk mechanisms substantially orchestrated by capability of transferring of molecules between several follicular cells types.

The expression of genes and/or proteins responsible for morphological changes within ovarian follicle or genes encoding proteins which regulate oocytes/ follicular cells growth and differentiation were well recognized on a pig model of folliculogenesis/oogenesis. However, processes responsible for regulation of cellular metabolism including cellular inducible signaling and/or metabolic pathways, it still must be significantly investigated. Additionally, the regulatory mechanisms responsible for macromolecules metabolisms belongs to the unexplored fields in both human and animal experimental reproductive biology. The experiments of this article are demonstrated for the first time on ontological group of genes encoding proteins which 
are responsible for „macromolecules metabolisms” in porcine oocytes. Our results led to discuss some possibilities of other ways of investigations based on „metabolome assays" in mammalian oocytes in relation to in vitro maturation capability.

\title{
MATERIAL AND METHODS
}

\begin{abstract}
ANIMALS
A total of 45 pubertal crossbred Landrace gilts, bred on a local, commercial farm, were used in this study. They had a mean age of 155 days (range 140 - 170 days) and a mean weight of $100 \mathrm{~kg}(95-120 \mathrm{~kg})$. All of the animals were housed under identical conditions and fed the same forage (depending on age and reproductive status). The experiments were approved by the Local Ethic Committee.
\end{abstract}

\section{COLLECTION OF PORCINE OVARIES AND CUMULUS-OOCYTE-COMPLEXES (COCS)}

Ovaries and reproductive tracts were recovered at slaughter and transported to the laboratory at $38^{\circ} \mathrm{C}$ in $0.9 \% \mathrm{NaCl}$ within 40 min.In order to provide optimal conditions for subsequent oocyte maturation and fertilization in vitro, the ovaries of each animal were placed in 5\% fetal bovine serum solution (FBS; Sigma-Aldrich Co., St. Louis, MO, USA) in PBS. Single large follicles $(>5 \mathrm{~mm})$ were then opened by puncturing with a $5 \mathrm{ml}$ syringe and $20-\mathrm{G}$ needle in a sterile Petri dish, and COCs were recovered. The COCs were washed three times in modified PBS supplemented with $36 \mu \mathrm{g} / \mathrm{ml}$ pyruvate, $50 \mu \mathrm{g} / \mathrm{ml}$ gentamycine, and $0.5 \mathrm{mg} / \mathrm{ml} \mathrm{BSA} \mathrm{(Sigma-Aldrich,} \mathrm{St.} \mathrm{Louis,} \mathrm{MO,}$ USA). COCs were selected under an inverted microscope Zeiss, Axiovert 35 (Lübeck, Germany), counted, and morphologically evaluated using the scale suggested by Jackowska et al. [12]. Only COCs of grade I with homogeneous ooplasm and uniform, compact cumulus cells were considered for the following steps of the experiment, resulting 300 grade I oocytes ( $3 \times \mathrm{n}=50$ before IVM, $3 \times \mathrm{n}=50$ after IVM).

\section{ASSESSMENT OF OOCYTE DEVELOPMENTAL COMPETENCE BY BCB TEST}

To perform the BCB staining test, oocytes were washed twice in modified Dulbecco PBS (DPBS) (Sigma-Aldrich, St. Louis, MO) supplemented with 50 IU/ 
$\mathrm{ml}$ penicillin, $50 \mu \mathrm{g} / \mathrm{ml}$ streptomycin (Sigma-Aldrich, St. Louis, MO, USA), 0.4\% BSA [w/v], $0.34 \mathrm{mM}$ pyruvate, and $5.5 \mathrm{mM}$ glucose (DPBSm).Thereafter, they were treated with $13 \mu \mathrm{M}$ BCB (Sigma-Aldrich, St. Louis, MO) diluted in DPBSm at $38.5^{\circ} \mathrm{C}$ and $5 \% \mathrm{CO}_{2}$ for $90 \mathrm{~min}$. Following the treatment, the oocyteswere transferred to DPBSm and washed twice. During the washing procedure, the oocytes were examined under an inverted microscope and classified as either stained blue $\left(\mathrm{BCB}^{+}\right)$or remained colourless $\left(\mathrm{BCB}^{-}\right)$. Immature oocytes have compact cumulus cell layers that require removal for further oocyte evaluation. Next, the $\mathrm{BCB}^{+} \mathrm{COCs}$ were first incubated with bovine testicular hyaluronidase (Sigma-Aldrich, St. Louis, MO, USA) for $2 \mathrm{~min}$ at $38^{\circ} \mathrm{C}$ to separate cumulus and granulosa cells. Cells were then removed by vortexing the $\mathrm{BCB}^{+}$oocytes in $1 \%$ sodium citrate buffer followed by mechanical displacement using a smalldiameter glass micropipette. Only the granulosa cell-free $\mathrm{BCB}^{+}$oocytes were used for subsequent IVM and microarray analysis.

\section{IN VITRO MATURATION OF PORCINE COCS}

After the first $\mathrm{BCB}$ test, the $\mathrm{COCs}$ which remained colourless (BCB-) were cultured in Nunclon ${ }^{\mathrm{TM}} \Delta 4$-well dishes in $500 \mu$ l of standard porcine IVM culture medium TCM-199 (tissue culture medium) with Earle's salts and $L$-glutamine, (Gibco BRL Life Technologies, Grand Island, NY, USA) supplemented with $2.2 \mathrm{mg} / \mathrm{ml}$ sodium bicarbonate (NacalaiTesque, Inc., Kyoto, Japan), $0.1 \mathrm{mg} / \mathrm{ml}$ sodium pyruvate (Sigma-Aldrich, St. Louis, MO, USA), $10 \mathrm{mg} / \mathrm{ml}$ BSA (bovine serum albumin), (Sigma-Aldrich, St. Louis, MO, USA), $0.1 \mathrm{mg} / \mathrm{ml}$ cysteine (Sigma-Aldrich, St. Louis, MO, USA), 10\% filtered porcine follicular fluid (v/v), and gonadotropin supplements at final concentrations of $2.5 \mathrm{IU} / \mathrm{ml} \mathrm{hCG}$ (Ayerst Laboratories, Inc., Philadelphia, PA, USA) and $2.5 \mathrm{IU} / \mathrm{ml}$ eCG (Intervet, Whitby, ON, Canada). Wells were covered with a mineral oil overlay and cultured for 44 $\mathrm{h}$ at $38^{\circ} \mathrm{C}$ under $5 \% \mathrm{CO}_{2}$. After cultivation, the $\mathrm{BCB}$ staining test was performed again, and $\mathrm{BCB}^{+}$oocytes were used for further experiments.

\section{RNA EXTRACTION FROM PORCINE OOCYTES}

The investigated Oocytes, before and after in vitro maturation were pooled into three independent samples for each experimental group. Total RNA was extracted from samples using TRI Reagent (Sigma, St Louis, MO, USA) and RNeasy MinElute cleanup Kit (Qiagen, Hilden, Germany). The amount of total mRNA was determined from the optical density at $260 \mathrm{~nm}$, and the RNA purity was estimated using the $260 / 280 \mathrm{~nm}$ absorption ratio (higher than 1.8) (NanoDrop spectrophotometer, 
Thermo Scientific, ALAB, Poland). The RNA integrity and quality were checked on a Bioanalyzer 2100 (Agilent Technologies, Inc., Santa Clara, CA, USA). The resulting RNA integrity numbers (RINs) were between 8.5 and 10 with an average of 9.2 (Agilent Technologies, Inc., Santa Clara, CA, USA). Furthermore, the RNA in each sample was diluted to a concentration of $100 \mathrm{ng} / \mu 1$ with an OD260/OD280 ratio of 1.8/2.0. From each RNA sample, $500 \mathrm{ng}$ of RNA were taken.

\section{MICROARRAY EXPRESSION ANALYSIS AND STATISTICS}

The Affymetrix procedure was previously described by Trejter et.al [36]. Total RNA (100 ng) from each pooled sample was subjected to two round, sense cDNA amplification (Ambion ${ }^{\circledR}$ WT Expression Kit). The obtained cDNA was used for biotin labeling and fragmentation by AffymetrixGeneChip ${ }^{\circledR}$ WT Terminal Labeling and Hybridization (Affymetrix). Biotin-labeled fragments of cDNA (5.5 $\mu \mathrm{g})$ were hybridized to the Affymetrix ${ }^{\circledR}$ Porcine Gene 1.1 ST Array Strip $\left(48^{\circ} \mathrm{C} / 20\right.$ h). Then, microarrays were washed and stained according to the technical protocol using the AffymetrixGeneAtlas Fluidics Station. The array strips were scanned employing Imaging Station of the GeneAtlas System. The preliminary analysis of the scanned chips was performed using AffymetrixGeneAtlasTM Operating Software. The quality of gene expression data was confirmed according to the quality control criteria provided by the software. The obtained CEL files were imported into downstream data analysis software.

All of the presented analyses and graphs were performed using Bioconductor and $\mathrm{R}$ programming languages. Each CEL file was merged with a description file. In order to correct background, normalize, and summarize results, we used the Robust Multiarray Averaging (RMA) algorithm. To determine the statistical significance of the analyzed genes, moderated t-statistics from the empirical Bayes method were performed. The obtained p-value was corrected for multiple comparisons using Benjamini and Hochberg's false discovery rate. The selection of significantly altered genes was based on a p-value beneath 0.05 and expression higher than two fold.

Differentially expressed genes were subjected to the selection of genes involved in morphogenesis and cellular differentiation. The differentially expressed gene list (separated for up- and down-regulated genes) was uploaded to DAVID software (Database for Annotation, Visualization and Integrated Discovery), where genes belonging to "Positive regulation of macromolecule metabolic process" GO term were obtained. The term "Positive regulation of macromolecule metabolic process" (GO:0010604) is defined as "Any process that increases the frequency, rate or extent of the chemical reactions and pathways involving macromolecules, any molecule of high relative molecular mass, the structure of which essentially 
comprises the multiple repetition of units derived, actually or conceptually, from molecules of low relative molecular mass.". It consist of 82197 anotated genes of which 3837 are anotated to Susscrofa organism.

Expression data of these genes was subjected to a hierarchical clusterization procedure, and their expression values were presented as a heat map. Besides predicting interactions, DAVID software also allowed performance of functional enrichments of GO terms based on previously uploaded gene sets from the "Positive regulation of macromolecule metabolic process" GO BP term. The top five GO terms that genes belong also to "Positive regulation of macromolecule metabolic process" GO BP were shown in (tab. 2). The relation between genes that belongs to other GO terms were further investigated by GeneAnswers R package and presented as Concept-gene network (fig. 2).

Interactions between differentially expressed genes/proteins belonging to "Positive regulation of macromolecule metabolic process" ontology group were investigated by STRING10 software (Search Tool for the Retrieval of Interacting Genes). The list of gene names was used as query for interaction prediction. The search criteria was based on co-occurrences of genes/proteins in scientific texts (text mining), coexpression, and experimentally observed interactions. The results of such analysis generated a gene/protein interaction network where the intensity of the edges reflected the strength of the interaction score.

\section{RESULTS}

To investigate oocyte transcriptome changes after in vitro maturation in relation to transctiptome profile of freshly isolated oocyte, before in vitro procedure (in Vivo).We performed whole gene expression analysis by Affymetrix ${ }^{\circledR}$ Porcine Gene 1.1 ST Array. In such assay expression of more than 12258 porcine transcripts was examined. The genes for which the fold change was higher than the cut-off value $($ fold $>|2|)$ and corrected $p$ value $(\operatorname{adj} p)<0.05$, were considered as differentially expressed. From the whole transcript that consist of 419 different genes, 379 genes were downregulated and 40 genes were up regulated in relation to the oocyte transcriptome before in vitro procedure.

Among these genes, genes belong to "Positive regulation of macromolecule metabolic process" gene ontology biological process term was extracted by DAVID (Database for Annotation, Visualization and Integrated Discovery) software. Up and down regulated gene sets were subjected to DAVID searching separately and only gene sets, where adj. $p$ value were lower than 0.05 were selected (tab. 1). This set of genes was subjected to hierarchical clusterization procedure and presented as heatmap (fig. 1). 
TABLE 1. Fold changes, adjusted $p$ values and ENTREZ gene ID of differentially expressed genes belonging to the "Positive regulation of macromolecule metabolic process" functional category from DAVID GEOTERM BP database. Symbols and names of the selected genes are also shown

\begin{tabular}{|c|c|c|c|}
\hline NAME & FOLD & ADJ.P.VALUE & ENTREZ GENE ID \\
\hline SH3D19 & 2.048643 & $4.651264 \mathrm{e}-02$ & 152503 \\
\hline SMARCA1 & 3.038212 & $1.475885 \mathrm{e}-02$ & 6594 \\
\hline NFAT5 & 2.899487 & $1.314546 \mathrm{e}-02$ & 10725 \\
\hline MAP3K1 & 2.711751 & $2.474846 \mathrm{e}-02$ & 4214 \\
\hline RORA & 2.604679 & $2.155377 \mathrm{e}-02$ & 6095 \\
\hline IKZF2 & 2.315499 & $2.982988 \mathrm{e}-03$ & 22807 \\
\hline VEGFA & 14.349387 & $1.912689 \mathrm{e}-03$ & 7422 \\
\hline ESR1 & 12.250422 & $5.221871 \mathrm{e}-04$ & 2099 \\
\hline PSMB4 & 2.025513 & $9.391490 \mathrm{e}-04$ & 5692 \\
\hline NR5A1 & 2.352096 & $1.888852 \mathrm{e}-03$ & 2516 \\
\hline CCND2 & 8.209570 & $1.788045 \mathrm{e}-04$ & 894 \\
\hline APP & 3.085100 & $5.602323 e-03$ & 351 \\
\hline SMAD4 & 2.718853 & $1.238681 \mathrm{e}-03$ & 4089 \\
\hline $\mathrm{IHH}$ & 3.278733 & $5.512614 \mathrm{e}-04$ & 3549 \\
\hline MEF2C & 2.204619 & $3.964010 \mathrm{e}-03$ & 4208 \\
\hline EDNRA & 5.990211 & $1.854220 \mathrm{e}-03$ & 1909 \\
\hline KIT & 2.323181 & $2.556350 \mathrm{e}-03$ & 3815 \\
\hline GJA1 & 4.833081 & $1.076763 \mathrm{e}^{-04}$ & 2697 \\
\hline INHBA & 4.144910 & $1.480362 \mathrm{e}-04$ & 3624 \\
\hline $\mathrm{AR}$ & 9.435182 & $1.383666 \mathrm{e}-04$ & 367 \\
\hline EGR1 & 2.658668 & $5.477006 \mathrm{e}-03$ & 1958 \\
\hline EGR2 & 6.042156 & $7.949861 \mathrm{e}-03$ & 1959 \\
\hline ECE1 & 2.529163 & $1.177804 \mathrm{e}-03$ & 1889 \\
\hline FOS & 18.941419 & $4.739475 \mathrm{e}-05$ & 2353 \\
\hline WWTR1 & 3.056215 & $2.540251 \mathrm{e}-04$ & 25937 \\
\hline INSR & 3.164401 & $1.912689 \mathrm{e}-03$ & 3643 \\
\hline MITF & 2.033927 & $6.329736 \mathrm{e}-03$ & 4286 \\
\hline
\end{tabular}




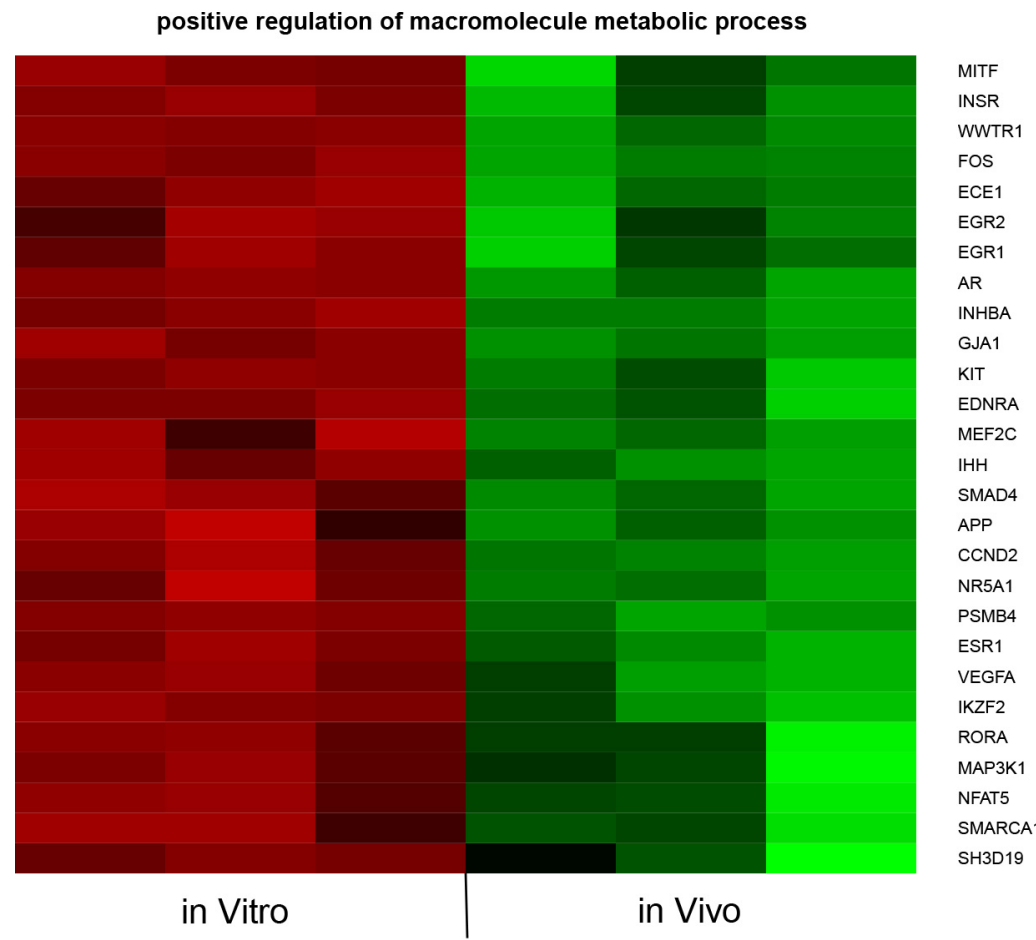

FIGURE 1. Heat map representation of differentially expressed genes belonging to the category "Positive regulation of macromolecule metabolic process" from GO.BP database. Arbitrary signal intensity acquired from microarray analysis is represented by colours (green, higher; red, lower expression). $\log 2$ signal intensity values were resized to Row Z-Score scale for any single genes (from -2 , the lowest expression to +2 , the highest expression)

Genes from one particular GO group will belong also to other different GO term categories. By this reason we perform functional enrichments of GO terms based on previously uploaded gene set from "Positive regulation of macromolecule metabolic process" GO BP term. Top five GO terms that genes belong also to "Positive regulation of macromolecule metabolic process" include GO terms such as "positive regulation of macromolecule metabolic process" "positive regulation of cellular metabolic process", "positive regulation of transcription from RNA polymerase II promoter", "positive regulation of gene expression", "transcription from RNA polymerase II promoter". GO BP term category was presented as table, where its category, term, number of genes that its share with "Positive regulation of macromolecule metabolic process", p-value and Benjamini and Hochberg's false discovery rate were shown (tab. 2). Categories were further investigated with GeneAnswers R package and the results were presented as concept-gene network (fig. 2). 
TABLE 2. Top five GO categories formed by genes differentially expressed belonging to the "bone development" ontology group. GO categories were generated in STRING software. GO ID (pathway ID), GO term description (pathway description), number of the genes belonging to appropriate category (count in gene set) are shown

\begin{tabular}{c|r|c|c|c|c}
\hline CATEGORY & TERM & COUNT & $\%$ & P-VALUE BENJAMINI \\
\hline GOTERM_BP_FAT & $\begin{array}{c}\text { positive regulation of cellular metabolic } \\
\text { process }\end{array}$ & 16 & 61,5 & $1,1 \mathrm{E}-7$ & $6,3 \mathrm{E}-5$ \\
\hline GOTERM_BP_FAT & $\begin{array}{c}\text { positive regulation of transcription from } \\
\text { RNA polymerase II promoter }\end{array}$ & 10 & 38,5 & $8,1 \mathrm{E}-7$ & $3,4 \mathrm{E}-4$ \\
\hline GOTERM_BP_FAT & positive regulation of gene expression & 12 & 46,2 & $9,5 \mathrm{E}-7$ & $3,2 \mathrm{E}-4$ \\
\hline GOTERM_BP_FAT & $\begin{array}{r}\text { transcription from RNA polymerase II } \\
\text { promoter }\end{array}$ & 12 & 46,2 & $1,3 \mathrm{E}-6$ & $3,6 \mathrm{E}-4$ \\
\hline GOTERM_BP_FAT & $\begin{array}{r}\text { positive regulation of nucleic acid-tem- } \\
\text { plated transcription }\end{array}$ & 11 & 42,3 & $1,3 \mathrm{E}-6$ & $3,2 \mathrm{E}-4$ \\
\hline
\end{tabular}

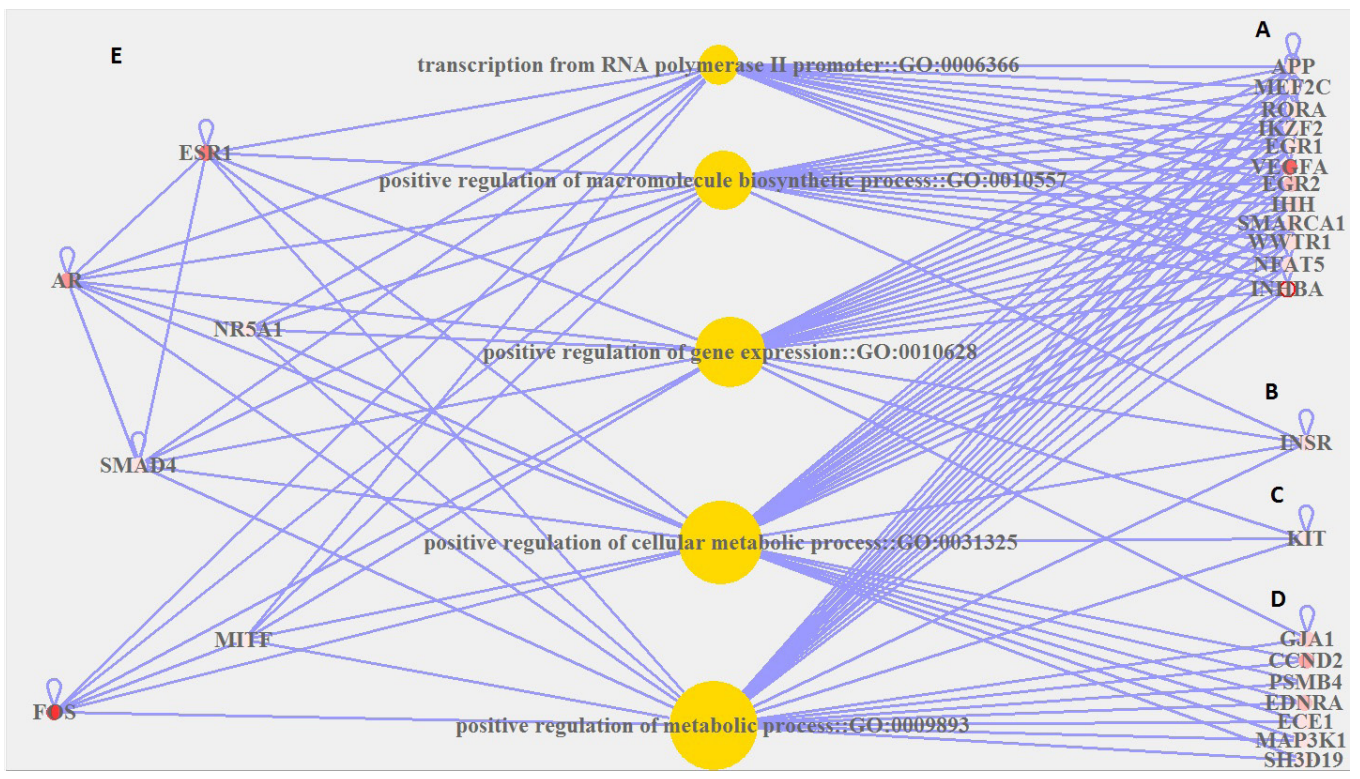

FIGURE 2. Concept-gene network which shows which differently expressed genes from "Positive regulation of macromolecule metabolic process" belongs to which of top five GO category that shares genes with "Positive regulation of macromolecule metabolic process". The genes are sorted for A) belonging to all five terms B) belonging to 4 terms $\mathbf{C}$ ) belonging to 3 terms, D) belonging to 2 terms and on the left side $\mathbf{E}$ ) genes with more complicated interactions. The intensity of the red color of the dots represents the fold change 
STRING-generated interaction network was generated among differentially expressed genes belonging to the "Positive regulation of macromolecule metabolic process" term. Applied prediction methods that used text mining, co-expression, experimentally observed interactions (fig. 3).

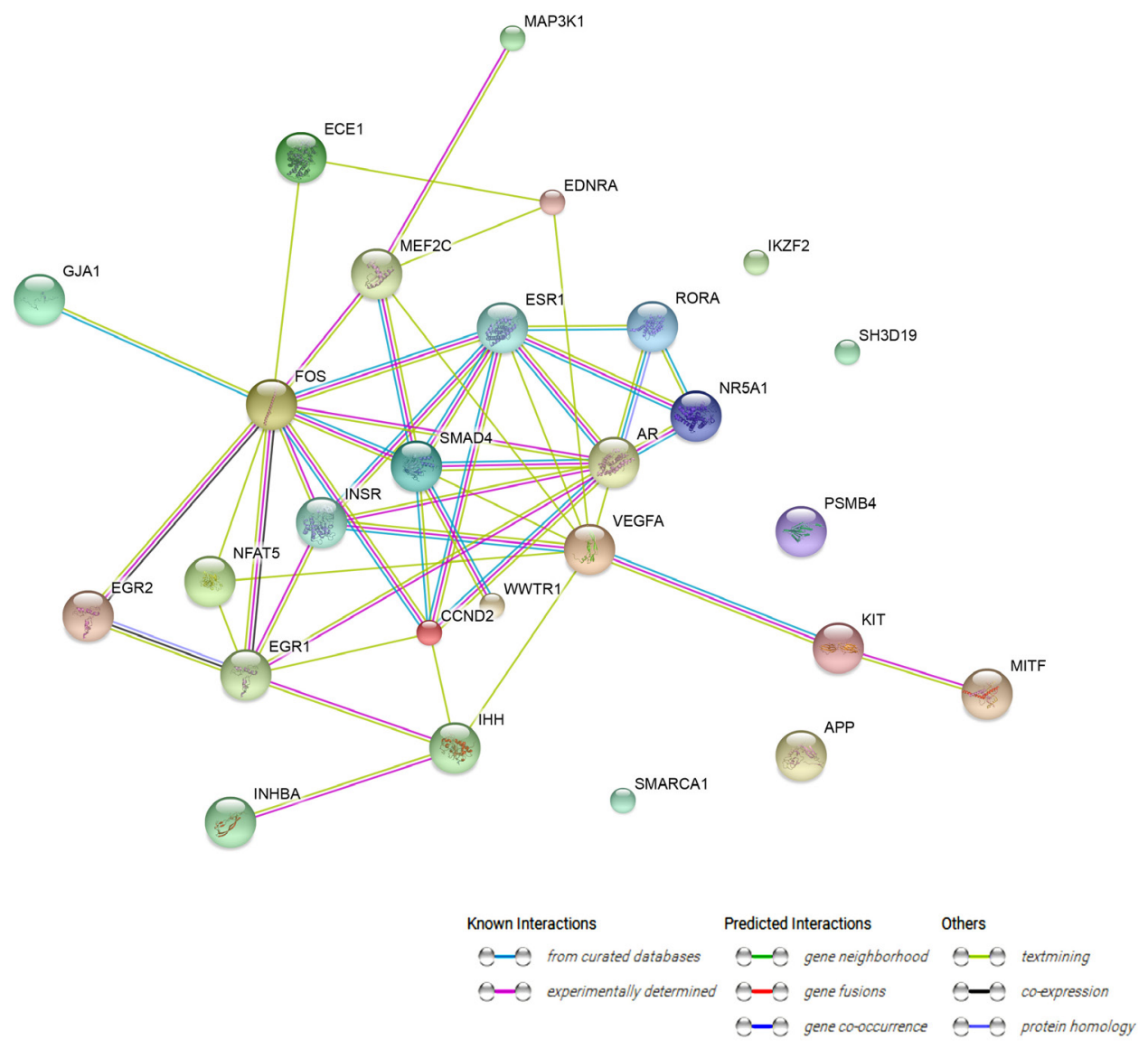

FIGURE 3. STRING-generated interaction network among differentially expressed genes belonging to the "Positive regulation of macromolecule metabolic proces" ontology group. Applied prediction methods: text mining, co-expression, experimentally observed interactions. The lines show which genes were co-mentioned in publication. So far other interactions had not been described

\section{DISCUSSION}

Heat map shows the expression of genes which belong to the category of "Positive regulation of metabolic Macromolecule" from GO. BP database. This group was formed by the genes responsible for a number of different metabolic 
changes characteristic of specific metabolic pathways. Despite the specificity of these genes, they might be involved in the maturation of oocyte.

It is shown that (MITF) is involved in making melanocytes and melanoma. Moreover, the gene is involved in the progression and cell cycle control [1]. Carreira et al. (2005) showed that MITF acts as an anti-proliferative and can induce the arrested G1 cell cycle. Stopping it is dependent on p21 cyclin-dependent kinase inhibitor gene (CIP1). These researchers also showed that MITF including RB1 activates the ability to efficient MITF transcription. As a result, MITF to exit the cell cycle and activation of cell differentiation [3]. Our research suggests that the MITF also involved in the proliferation of melanocytes and melanoma cells may also take part in the ova maturation and proliferation of the reproductive system.

Another test gene is the insulin receptor (INSR). Gene mutations associated with INSR are mostly associated with the presence of insulin resistance [26]. It was also shown that the gene mutation INSR in patients with polycystic ovary syndrome (hyperandrogemia, oligoamenorrhea, and hirsutism) [27]. The effect of defects in the gene INSR is impaired ovulation and thus oocyte maturation. Our study thus confirms that the gene INSR is an important factor involved in the process of maturation of oocytes.

Molecular analysis of individual tissues revealed that the gene WW domaincontaining transcription regulatorr1 (WWTR1) shows expression in kidney, heart, lung, and placenta and testis. Another name of WWTR1 is TAZ [14]. During his research, Cui et al. (2003) noted that the TAZ shown to interact with the gene RUNX2. Removing TAZ inhibits the expression of Runx2 [6]. In other studies, we know that Runx2 is a key transcription factor acting in the differentiation of the cells. Many studies have shown a correlation between the gene expression of Runx2 and ovulation [8]. It is believed, therefore, that WWTR1 in correlation with Runx2 is involved in causing maturation of oocytes.

Muller et al. (1983) observed that the level of transcriptome c-fos gene is higher in fetal membranes than in the other tissues of the body. Further it suggests that the proteins encoded by the FOS are associated with the cells performing protective functions and nutrients to the fetus [28]. In addition, Visvader et al. (1988) found that FOS may mediate the induction of nerve growth factor [39]. The expression of FOS has also been demonstrated in trials for the development of germ cells. The protein products of this gene plays an important role in cell proliferation and differentiation. As well as in cell signaling pathways. Wang et al. and Johnson et al., have demonstrated that mice with impaired FOS gene expression showed the loss of viability at birth, reduced muscle mass and abnormal fetal gametogenesis $[40,13]$. It can therefore be assumed that the FOS is important in the maturation of oocytes.

Another gene belonging to the group of "positive regulation of macromolecule metabolic process" is Endothelin-converting enzyme 1 (ECE1). Maggi et al. ECE1 showed expression in the nasal cavity of the human fetus. These researchers 
also showed that the biological activity ECE1 is present in the GnRH-secreting neuronal cells [22].

Early growth response 1 (EGR1) is another gene which has a higher expression in vivo maturation of the oocytes. EGR1 is involved in stimulating the cells to cell division (mitosis). Lee et al. (1996) conducted a study in mice blocked gene Egr1. We found that females of a defective Egr1 showed infertility resulting from deficiency of luteinizing hormone (LH) [21]. Discontinuation of our research can therefore assume that this gene is involved not only in regulating the secretion of LH but also in the process of oocyte maturation in vivo.

Nagarajan et al. in their study they showed that early growth response 2 (EGR2) is a factor in inducing the Schanna cells [29]. Relating this to our research, we believe that during the maturation of oocytes in vitro increases the expression of Egr1 which may be associated with subsequent myelination of nerve fibers during intrauterine development.

Another gene which grows during maturation in vivo is androgen receptor (AR). It belongs also to the group of "positive regulation of macromelecule metabolic process." This factor is involved in the regulation of signalling pathways Wnt and Notch MAPK. Expression of AR is associated with the secretion of androgens that control growth of prostate cells [30]. Referring to our studies, we conclude that increased level of AR expression also occurs during maturation of oocytes in vivo in female. Other studies were carried out on human models have shown that expression of AR in females is associated with the occurrence of a particular phenotype. Among other things, in women with polycystic ovary syndrome (PCOS) is the lack of ovulation and irregular menstrual cycles [9, 25]. The findings suggest that in the maturation of oocytes is also involved inhibin beta A (INHBA). Inhibin is a gonadal glycoprotein hormone that regulate the secretion of pituitary FSH. INHBA is one of the two forms of inhibin. Many years ago, Meunier et al. they suggested that the inhibin in various embodiments and with various intensity express their expression in many tissues, including gonadal tissues. This suggests versatility of inhibins [23]. Under normal physiological conditions, inhibin produced by granulosa cells during folliculogenesis. Lappohn et al. found inhibin also produced by granullosa cell tumor. Inhibin is therefore a good indicator of the quality of the occurrence of ovarian follicles processes [18]. It is suggested, therefore, that INHBA involved in processes related to the maturation of oocytes.

From the point of view of our research gene, it's important to mention the gap junction protein, alpha 1 (GJA1). Gene GJA1 is responsible for encoding transmembrane proteins - cennexin (CXS). The most common connexin is a connexin-43 (Cx43). CXS are responsible for the formation of gab junction channel, intecellulars channel, which interconnect the cells between them. These channels allow for free communication between cells [20]. Tsai et al. in their 
study show that the expression of connexin $(\mathrm{Cx} 43, \mathrm{CX} 45, \mathrm{Cx} 37)$ reflects the maturity of the follicles. In a detailed study we found that connexin expressed in the granulosa cells from luteinized follicular. A clear decrease in the expression of connexins (except for $\mathrm{Cx} 43$ ) was observed in follicles larger than $5.5 \mathrm{ml}$. That $\mathrm{Cx} 43$ showed a better prognosis for IVF [38]. Given the fact that GJA1 involved in the formation of junctions and thus the cell may function reasonably well, our studies suggest that the maturation of oocytes in vivo GJA1 type connection have an import ant role. As a result, the oocyte may communicate freely with the surrounding environment, exchanging substances from the external environment.

Another important factor involved in the process of maturation of oocytes according to our research is to KIT (tyroisine receptor) is involved in diverse processes: hematopoiesis, melanogenesis, especially in the gamegenesis [31]. Kit gene knockout causes decreased fertility, female mammals, impaired follicular development, which affects the process of oocyte maturation. Kissel et al. $\mathrm{He}$ suggested in their research that KIT mediates signalling path $\mathrm{P} 13 \mathrm{~K}$, which is critical in the gametogenesis [16]. KIT receptor tyrosine kinase plays a key role in the growth of germ cells, both in vivo and in vitro.

The highest level of expression of Endothelin receptor type A (EDNRA) occurs in the aorta and human mesangial cells [10]. In addition, our research suggests that this gene is involved in the maturation of oocytes.

Mads box transcription enhancer factor 2, PolyPeptide C (MEF2C) is another factor that based on our research belongs to the "positive regulation of macromelecule metabolic process." According to many authors and their research they proved that MEF2C participates in the development and differentiation of smooth and skeletal muscle cells $[2,4]$. In addition, our studies demonstrate that increased expression of this gene occurs during oocyte maturation in vivo.

The key role of Indian hedgehog (IHH) is mediating the action of PGR in the uterus. IHH expression plays an important role in communication between the epithelium of the uterus and the embryo implantation [20]. It was also shown that the IHH has a positive effect on the progesterone receptor (PGR).

Smad4 gene is involved in the signal path encoding a protein involved in signal transduction, the transforming factor (TGFB1) and bone morphogenic proteins through mediation in the transcriptional activation of target genes. Smad4 belong to the Smads protein family, which are necessary to respond most FGFB and BMP signalling pathway [34].

APP gene is mainly related to Alzheimer's and Parkinson's disease, and thus the disease associated with the nervous system [35]. According to our studies, it is anticipated that is also involved in the maturation of oocytes since its expression is increased when cultured in vivo. The results of our studies show that when cultured in vivo oocytes increased expression of Cyclin D2 (CCDN2). This gene in an animal model is responsible for the growth of Schwann cells [15]. 
Nuclear receptor subfamily 5 (NR5A1) is a transcription factor belonging to the nuclear receptor. Regulates the expression of genes associated with reproduction, gender differentiation and steroidogenesis [37]. It is suggested, therefore, that this factor is also involved in the maturation of oocytes.

It is known that estrogen receptor 1 (ESR1) is necessary for the proper functioning of the reproductive system in mammals. Many authors have proved in their studies that males and mainly females with a mutation in the gene ESR1 have defects in male reproductive organs which in turn leads to infertility $[17,5]$. Our research confirms the crucial role of ESR1 in the proper functioning of the ovaries. Thus, increased expression of ESR1 the culture oocytes in vivo, suggesting a key role in this process.

It is believed that the increase in gene expression, such as vascular endothelial growth factor A (VEGF), proteasome subunit beta type 4 (PDMB4) Ikaros family zinc finger 2 (IKZF2) related morphan receptor A (RORA), mitogen-activated protein kinase 1 (MAP3K1 or MEKK1) Nuclear factor of activated T-cells 5 (NFAT5) SMARCA1, SH3 domain protein 19 (SH3D19) is linked to a more efficient maturation of oocytes in vivo. These genes are responsible for a many different changes in mammalian cells [41, 19].

Vascular endothelial growth factor A (VEGF) under physiological conditions is responsible for the induction of angiogenesis [32].

Ikaros family zinc finger 2 (IKZF2) is a gene responsible for regulating cell differentiation [11]. The study also suggests that factors such as related morphan receptor A (RORA), which under physiological conditions is expressed in mesenchymal stem cells of the bone marrow may be involved in the maturation of oocytes in vivo. Under physiological conditions, the protein product of the gene RORA works by modulating on bone matrix [34].

Mitogen-activated protein kinase 1 (MAP3K1 or MEKK1) under physiological conditions acts as antiapoptotic. Only after cleavage of caspases to induce apoptosis [33].

\section{ACKNOWLEDGEMENTS}

Publication of this article was made possible by grant number 502-14-0222736710694 from Poznan University of Medical Sciences

\section{REFERENCES}

[1] Bemis LT, Chen R, Amato CM, Classen EH, Robinson SE, Coffey DG, Erickson PF, Shellman YG, RoBINSON WA. MicroRNA-137 targets microphthalmia-associated transcription factor in melanoma cell lines. Cancer Res. 2008; 68: 1362-1368. 
[2] Breitbart RE, Liang C, Smoot LB, Laheru DA, Mahdavi V, Nadal-Ginard B. A fourth human MEF2 transcription factor, hMEF2D, is an early marker of the myogenic lineage. Development. 1993; 118: 1095-1106.

[3] Carreira S, Goodall J, Aksan I, La Rocca Sa, Galibert MD, Denat L, Larue L, Goding CR. Mitf cooperates with $\mathrm{Rb} 1$ and activates $\mathrm{p} 21(\mathrm{Cip} 1)$ expression to regulate cell cycle progression. Nature. 2005; 433: 764-769.

[4] Chen SL, Loffler KA, Chen D, Stallcup Mr, Muscat GeO. The coactivator-associated arginine methyltransferase is necessary for muscle differentiation: CARM1 coactivates myocyte enhancer factor-2. J Biol Chem. 2002; 277: 4324-4333.

[5] Couse JF, Hewitt SC, Bunch Do, Sar M, Walker VR, Davis BJ, Korach KS. Post natal sex reversal of the ovaries in mice lacking estrogen receptors alpha and beta. Science. 1999; 286: 2328-2331.

[6] Cui CB, Cooper LF, Yang X, Karsenty G, Aukhil I. Transcriptional coactivation of bone-specific transcription factor Cbfa1 by TAZ. Mole Cell Biol. 2003; 23: 1004-1013.

[7] De Bock M, Kerrebrouck M, Wang N, Leybaert L. Neurological manifestations of oculodentodigital dysplasia: a Cx43 channelopathy of the central nervous system? Front. Pharm. 2013; 4: 120.

[8] FAn HY, Liu Z, JOHNSON PF, Richards JS. CCAAT/enhancer-binding proteins (C/EBP)-alpha and -beta are essential for ovulation, luteinization, and the expression of key target genes. MolEndocrinol. 2011; 25: 253-268.

[9] Hickey T, Chandy A, Norman RJ. The androgen receptor CAG repeat polymorphism and X-chromosome inactivation in Australian Caucasian women with infertility related to polycystic ovary syndrome. J Clin Endocr Metab. 2002; 87: 161-165.

[10] Hosoda K, Nakao K, Tamura N, Arai H, Ogawa Y, Suga S, Nakanishi S, Imura H. Organization, structure, chromosomal assignment, and expression of the gene encoding the human endothelin-A receptor. J Biol Chem. 1992; 267: 18797-18804.

[11] Hosokawa Y, Maeda Y, Seto M. Human Helios, an Ikaros-related zinc finger DNA binding protein: cDNA cloning and tissue expression pattern. Immunogenetics. 1999; 50: 106-108.

[12] Jackowska M, Kempisty B, Antosik P, Bukowska D, Budna J, Lianeri M, et al. The morphology of porcine oocytes is associated with zona pellucida glycoprotein transcript contents. Reproductive biology. 2009; 9: 79-85.

[13] Johnson RS, Sitegelman BM, Papaioannou V. Pleiotropic effects of a null mutation in the c-fos proto-oncogene. Cell. 1992; 71: 577-586.

[14] Kanai F, Marignani PA, Sarbassova D, Yagi R, Hall RA, Donowitz M, Hisaminato A, Fujiwara T, Ito Y, CANTLey LC, YAfFe MB. TAZ: a novel transcriptional co-activator regulated by interactions with 14-3-3 and PDZ domain proteins. EMBO J. 2000; 19: 6778-6791.

[15] Kim HA, Pomeroy SL, Whoriskey W, Pawlitzky I, Benowitz LI, Sicinski P, Stiles CD, Roberts TM. A developmentally regulated switch directs regenerative growth of Schwann cells through cyclin D1. Neuro. 2000; 26: 405-416.

[16] Kissel H, Timokhina I, Hardy MP, Rothschild G, Tajima Y, Soares V, Angeles M, Whitlow SR, Manova K, Besmer P. Point mutation in Kit receptor tyrosine kinase reveals essential roles for Kit signaling in spermatogenesis and oogenesis without affecting other Kit responses. EMBO J. 2000; 19: $1312-1326$.

[17] KoRACH KS. Insights from the study of animals lacking functional estrogen receptor. Science 1994; 266: 1524-1527.

[18] Lappohn RE, Burger HG, Bouma J, Bangah M, Krans M, de Bruinn HWA. Inhibin as a marker for granulosa-cell tumors. New Eng J Med. 1989; 321: 790-793.

[19] LazZaro MA, PicketTs DJ. Cloning and characterization of the murine Imitation Switch (ISWI) genes: differential expression patterns suggest distinct developmental roles for Snf2h and Snf21. J Neurochem. 2001; 77: 1145-1156.

[20] Lee K, Jeong J, Kwak I, Yu C-T, Lanske B, Soegiarto DW, Toftgard R, Tsai M-J, Tsai S, Lydon JP, DeMAYo FJ. Indian hedgehog is a major mediator of progesterone signaling in the mouse uterus. $\mathrm{Na}$ ture Genet. 2006; 38: 1204-1209. 
[21] Lee SL, Sadovsky Y, Swirnoff AH, Polish JA, Goda P, GavrilinaG, Milbrandt J. Luteinizing hormone deficiency and female infertility in mice lacking the transcription factor NGFI-A (Egr-1). Science. 1996; 273: 1219-1221.

[22] Maggi M, Barni T, Fantoni G, Mancina R, Pupilli C, Luconi M, Crescioli C, Serio M, Vannelli GB. Expression and biological effects of endothelin-1 in human gonadotropin-releasing hormone-secreting neurons. J Clin Endocr Metab. 2000; 85: 1658-1665.

[23] Meunier H, Rivier C, Evans RM, Vale W. Gonadal and extragonadal expression of inhibin alpha, beta-A and beta-B subunits in various tissues predicts diverse functions. Proc Nat Acad Sci. 1988; 85: $247-251$.

[24] Meyer T, Kneissel M, Mariani J, Fournier B. In vitro and in vivo evidence for orphan nuclear receptor ROR-alpha function in bone metabolism. Proc Nat Acad Sci. 2000; 97: 9197-9202.

[25] Mifsud A, Ramirez S, Yong EL. Androgen receptor gene CAG trinucleotide repeats in anovulatory infertility and polycystic ovaries. J Clin Endocr Metab. 2000; 85: 3484-3488.

[26] Moller De, Cohen O, Yamaguchi Y, Assiz R, Grigorescu F, Eberle A, Morrow LA, Moses AC, Flier JS. Prevalence of mutations in the insulin receptor gene in subjects with features of the type A syndrome of insulin resistance. Diabetes. 1994; 43: 247-255.

[27] Moller DE, Flier JS. Detection of an alteration in the insulin-receptor gene in a patient with insulin resistance, acanthosis nigricans, and the polycystic ovary syndrome (type A insulin resistance). New Eng J Med. 1988; 319: 1526-1529.

[28] Muller R, Tremblay JM, Adamson ED, Verma IM. Tissue and cell type-specific expression of two human c-onc genes. Nature. 1983; 304: 454-456.

[29] Nagarajan R, Svaren J, Le N, Araki T, Watson M, Milbrandt J. EGR2 mutations in inherited neuropathies dominant-negatively inhibit myelin gene expression. Neuron. 2001; 30: 355-368.

[30] Nantermet PV, Xu J, Yu Y, Hodor P, Holder D, Adamski S, Gentile Ma, Kimmel DB, Harada S, Gerhold D, Freedman LP, Ray WJ. Identification of genetic pathways activated by the androgen receptor during the induction of proliferation in the ventral prostate gland. J Biol Chem. 2004; 279: 1310-1322.

[31] Rothschild G, Sottas CM, Kissel H, Agosti V, Manova K, Hardy MP, Besmer P. A role for Kit receptor signaling in Leydig cell steroidogenesis. Biol Reprod. 2003; 69: 925-932.

[32] Ruhrberg C, Gerhardt H, Golding M, Watson R, Ioannidou S, Fujisawa H, Betscholtz C, Shima DT. Spatially restricted patterning cues provided by heparin-binding VEGF-A control blood vessel branching morphogenesis. Genes Dev. 2002; 16: 2684-2698.

[33] Schlesinger TK, Bonvin C, Jarpe MB, Fanger GR, Cardinaux J-R, Johnson GL, Widmann C. Apoptosis stimulated by the 91-kDa caspase cleavage MEKK1 fragment requires translocation to soluble cellular compartments. J Biol Chem. 2002; 277: 10283-10291.

[34] Shioda T, Lechleider RJ, Dunwoodie SL, Li H, Yahata T, de Caestecker MP, Fenner MH, Roberts AB, ISSELBACHER KJ. Transcriptional activating activity of Smad4: roles of SMAD hetero-oligomerization and enhancement by an associating transactivator. Proc Nat Acad Sci. 1998; 95: 9785-9790.

[35] Tanzi RE, Vaula G, Romano DM, Mortilla M, Huang Tl, Tupler RG, Wasco W, Hyman BT, Haines JL, Jenkins BJ, Kalaitsidaki M, Warren aC, Mcinnis MC, Antonarakis SE, Karlinsky H, Percy ME, Connor L, Growdon J, Crapper-McLachlan DR, Gusella JF, St. George-Hyslop PH. Assessment of amyloid beta-protein precursor gene mutations in a large set of familial and sporadic Alzheimer disease cases. Am J Hum Genet. 1992; 51: 273-282.

[36] Trejter M, Hochol A, Tyczewska M, Ziolkowska A, Jopek K, Szyszka M, et al. Sex-related gene expression profiles in the adrenal cortex in the mature rat: microarray analysis with emphasis on genes involved in steroidogenesis. International journal of molecular medicine. 2015; 35: 702-14.

[37] Tremblay JJ, Viger RS. A mutated form of steroidogenic factor 1 (SF-1 G35E) that causes sex reversal in humans fails to synergize with transcription factor GATA-4. J Biol Chem. 2003; 278: 42637-42642. 
[38] Tsai M-Y, Lan K-C, Huang K-E, Huang F-J, Kung F-T, Chang S-Y. Significance of mRNA levels of connexin37, connexin43, and connexin 45 in luteinized granulosa cells of controlled hyperstimulated follicles. Fertil Steril. 2003; 80: 1437-1443.

[39] Visvader J, Sassone-Corsi P, Verma IM. Two adjacent promoter elements mediate nerve growth factor activation of the c-fos gene and bind distinct nuclear complexes. Proc Nat Acad Sci. 1988; 85: 9474-9478.

[40] Wang Z-Q, Grigoriadis AE, Mohle-Steinlein U, Wagner EF. A novel target cell for c-fos-induced oncogenesis: development of chondrogenictumours in embryonic stem cell chimeras. EMBO J. 1991; 10: $2437-2450$.

[41] YAM JWP, Jin D-Y, So CW, ChAn LC. Identification and characterization of EBP, a novel EEN binding protein that inhibits Ras signaling and is recruited into the nucleus by the MLL-EEN fusion protein. Blood. 2004; 103: 1445-1453.

Editor -

Bartosz Kempisty

Department of Histology and Embryology, Department of Anatomy

Poznań University of Medical Sciences

6 Święcickiego St., 60-781 Poznań, Poland

tel./fax: +48618546418/+48618546440

e-mail:bkempisty@ump.edu.pl 